\title{
Sunlight Exposure: A Protective Role in the Development of Myopia
}

\author{
Syed Ali Hasan Naqvi ${ }^{1}$, Zaka Ur Rehman², Tehmina Nazir ${ }^{3}$, Amna Rizwan ${ }^{4}$, Hassan Raza ${ }^{5}$ and Naila Obaid ${ }^{3}$ \\ ${ }^{1}$ Department of Cornea, Al-Shifa Trust Eye Hospital, Rawalpindi, Pakistan \\ ${ }^{2}$ Department of General Medicine, University Clinic Rostock, Germany \\ ${ }^{3}$ Department of Ophthalmology, Fauji Foundation Hospital, Rawalpindi, Pakistan \\ ${ }^{4}$ Department of Retina, King Edward Medical University, Lahore, Pakistan \\ ${ }^{5}$ Department of Glaucoma, Al-Shifa Trust Eye Hospital, Rawalpindi, Pakistan
}

\begin{abstract}
The study objective was to assess the correlation of time outdoors in sunlight hours with spherical equivalent refraction (SER) and other variables. This was a cross-sectional study carried out in the Fauji Foundation Hospital, Rawalpindi, between January and April 2019. A total of 110 Individuals were included via convenient sampling, with myopia defined as having at least -0.5 D (SER $\leq-0.5 \mathrm{D})$. Collection of Questionnaires with interviews regarding eye care behaviour along with auto-refraction was done, followed by calculation of spherical equivalent refraction. Those having high myopia of 6 D or more (SER $\leq-6$ D), hyperopia of $0.5 \mathrm{D}$ or more (SER $\geq+0.5 \mathrm{D})$, and history significant for ocular trauma and surgeries, were excluded. After data cleaning and their entry, analyses were done using SPSS version 26. The mean age data, available for 105 individuals, was $15.4 \pm 3.69$ years. Spearman's correlation was used for right SER with time outdoors in summers $(r=+0.25, p=0.008)$ and winters $(r=$ $+0.243, p=0.010$ ), indicating an inverse relationship with myopia. Females had more myopic refraction than males, but the independent sample t-test was not significant. Logistic regression was used and a protective effect was found for both summer and winter time outdoors, while education level was associated with myopia.
\end{abstract}

Key Words: Myopia, Spherical equivalent refraction (SER), Sunlight exposure.

How to cite this article: Naqvi SAH, Rehman ZU, Nazir T, Rizwan A, Raza H, Obaid N. Sunlight Exposure: A Protective Role in the Development of Myopia. J Coll Physicians Surg Pak 2021; 31(09):1126-1128.

The international classification of diseases (ICD-11) defines myopia as 'A refractive error in which rays of light entering the eye parallel to the optic axis are brought to a focus in front of the retina when ocular accommodation is relaxed. This usually results from the eyeball being too long from front to back, but can be caused by an overly curved cornea, a lens with increased optical power, or both. It is also called nearsightedness'. The prevalence of myopia has been slowly increasing over the years throughout the world, with an expected increase of up to $49.8 \%$ of the world by $2050 .^{1}$

Although myopia is a multifactorial disease with a hereditary etiology, it is clear that environmental factors are involved. Apart from the cosmetic inconvenience, many complications are associated with this condition.

Correspondence to: Dr. Syed Ali Hasan Naqvi, Department of Cornea, Al-Shifa Trust Eye Hospital, Rawalpindi, Pakistan

E-mail: doc.ali1911@gmail.com

Received: February 22, 2021; Revised: May 30, 2021;

Accepted: June 19, 2021

DOI: https://doi.org/10.29271/jcpsp.2021.09.1126
It is one of the leading causes of blindness, increasing the risk of cataracts, glaucoma, myopic macular degeneration, and retinal detachment, ${ }^{2}$ while increasing the economic burden that comes with these conditions. Some of the risk factors include education levels, intensive near work, urbanization, and lack of ultraviolet-B exposure. Importantly, time outdoors has been used as an estimate of ultraviolet light exposure from sunlight. ${ }^{3}$ Some studies report a weak effect on myopia for the rural population, ${ }^{4}$ however, which may be explained by the higher levels of baseline exposure in such settings compared to the urban population.

This was a cross-sectional study, conducted on individuals aged 10-22 years, from both urban and rural backgrounds, presenting to the general OPD of Fauji Foundation Hospital, Rawalpindi, between January and April 2019. Approval of the Ethics Committee was obtained, and a convenient sampling technique was used. Those having high myopia of $6 D$ or more (SER $\leq-6 D$ ), hyperopia of $0.5 D$ or more (SER $\geq+0.5 D$ ), and history significant for ocular trauma or surgeries, were excluded. In the final analysis, 110 individuals were included. Data were collected using questionnaires and interviews. 
Table IA: Logistic regression for summers.

\begin{tabular}{|c|c|c|c|c|c|c|c|c|}
\hline \multirow{2}{*}{ Determinants } & \multicolumn{4}{|c|}{ Univariate } & \multicolumn{4}{|c|}{ Multivariate } \\
\hline & B & Exp(B) & $95 \% \mathrm{Cl}$ & p-value & B & Exp(B) & $95 \% \mathrm{Cl}$ & p-value \\
\hline \multicolumn{9}{|l|}{ Time outdoors } \\
\hline$\leq 2$ hours & 0.841 & 2.318 & $1.072-5.013$ & 0.033 & 1.177 & 3.244 & $1.370-7.682$ & 0.007 \\
\hline$>2$ hours & \multicolumn{4}{|c|}{ Reference } & \multicolumn{4}{|c|}{ Reference } \\
\hline \multicolumn{9}{|l|}{ Education } \\
\hline Primary & \multicolumn{4}{|c|}{ Reference } & \multicolumn{4}{|c|}{ Reference } \\
\hline Middle & 0.833 & 2.30 & $0.729-7.254$ & 0.155 & 0.927 & 2.528 & $0.763-8.378$ & 0.129 \\
\hline Secondary & 1.792 & 6.00 & $1.560-23.072$ & 0.009 & 2.101 & 8.173 & $1.957-34.129$ & 0.004 \\
\hline Intermediate & 0.288 & 1.333 & $0.321-5.538$ & 0.692 & 0.419 & 1.521 & $0.345-6.707$ & 0.580 \\
\hline Graduate & 2.079 & 8.000 & $1.279-50.04$ & 0.026 & 2.525 & 12.488 & $1.827-85.359$ & 0.010 \\
\hline
\end{tabular}

Table IB: Logistic regression for winters.

\begin{tabular}{|c|c|c|c|c|c|c|c|c|}
\hline \multirow{2}{*}{ Determinants } & \multicolumn{4}{|c|}{ Univariate } & \multicolumn{4}{|c|}{ Multivariate } \\
\hline & B & $\operatorname{Exp}(B)$ & $95 \% \mathrm{Cl}$ & p-value & B & $\operatorname{Exp}(B)$ & $95 \% \mathrm{Cl}$ & p-value \\
\hline \multicolumn{9}{|l|}{ Time outdoors } \\
\hline$\leq 2$ hours & 0.851 & 2.342 & $1.065-5.151$ & 0.034 & 1.225 & 3.404 & $1.392-8.324$ & 0.007 \\
\hline$>2$ hours & \multicolumn{4}{|c|}{ Reference } & \multicolumn{4}{|c|}{ Reference } \\
\hline \multicolumn{9}{|l|}{ Education } \\
\hline Primary & \multicolumn{4}{|c|}{ Reference } & \multicolumn{4}{|c|}{ Reference } \\
\hline Middle & 0.833 & 2.30 & $0.729-7.254$ & 0.155 & 0.865 & 2.374 & $0.715-7.883$ & 0.158 \\
\hline Secondary & 1.792 & 6.00 & $1.560-23.07$ & 0.009 & 2.144 & 8.537 & $2.026-35.982$ & 0.003 \\
\hline Intermediate & 0.288 & 1.333 & $0.321-5.538$ & 0.692 & 0.621 & 1.861 & $0.412-8.402$ & 0.420 \\
\hline Graduate & 2.079 & 8.000 & $1.279-50.04$ & 0.026 & 2.579 & 13.179 & $1.923-90.327$ & 0.009 \\
\hline
\end{tabular}
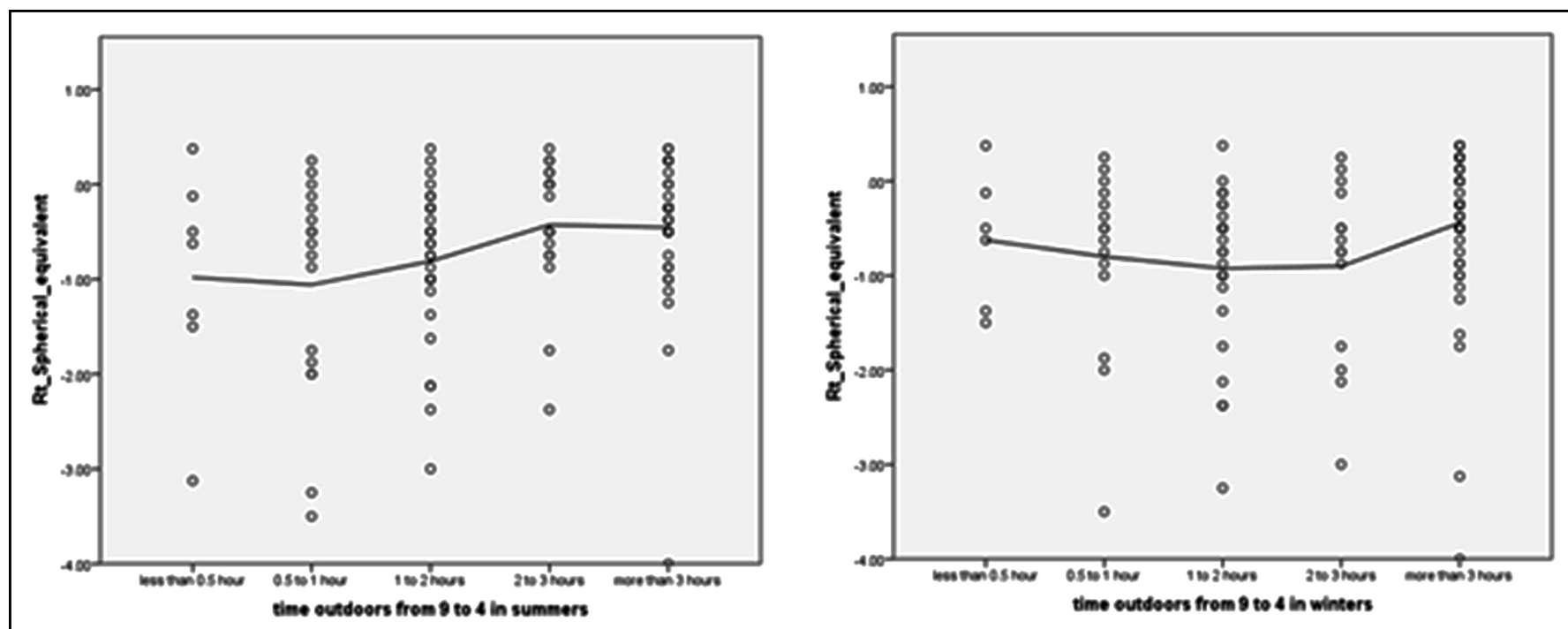

Figure 1: Right SER with time outdoors in summers and winters

Auto-refraction was done and spherical equivalent was calculated as sphere $+1 / 2$ cylinder. The questionnaire was adapted from the Aga Khan sun exposure ${ }^{5}$ and the Sujiatun eye study questionnaires. ${ }^{6}$

Individuals were asked about the time spent in daylight hours, the usual weather in summers and winters, the amount of time spent on weekdays and weekends in different activities, and the time spent in sports activities, among other variables. Questionnaire data were checked before entering into the computer, and those with missing data were omitted. Data analyses were done using SPSS version 26 software. The right and left eye spherical equivalent associations were high (Pearson's $r=0.81, p<0.01$ ) and so the right eyes were used for analyses.

Quantitative data were expressed with mean and standard deviations, where applicable, and qualitative data were expressed as numbers and percentages. Pearson's and Spearman's correlations were used for continuous and categorical variables, respectively; while multivariate logistic regression was used to analyse the data, including variables found to be significant in univariate analysis. For the regression model, time outdoors was included as a 2-variable category, i.e., less than or equal to, and more than 2 hours, to make the number of individuals larger in each group. Data for Summers and Winters were analysed, separately, defining the outcome variable as non-myopes and myopes, the latter having at least 
$-0.5 \mathrm{D}$ of power (SER $\leq-0.5 \mathrm{D})$. The significance level was set at $5 \%$.

There were $75(68.2 \%)$ men and 35 (31.8\%) women, with the mean age being $15.4 \pm 3.69$ years. There were $61(55.5 \%)$ myopes, and 49 (44.5\%) emmetropes. Education levels varied from less than primary to university degrees, with the majority of the individuals in middle school. For the perceived perception of sunlight exposure at home, 23 (20.9\%) reported poor, 38 (34.5\%) neutral, and 49 (44.5\%) reported adequate sunlight exposure at home. This was also positively correlated with right SER (Spearman's $r=0.2, p=0.036$ ).

The average right SER for males was -0.548D (SD: 0.65) and -0.932D (SD: 1.19) for females, but the independent sample ttest was not significant. Spearman's correlation between time outdoors with right eye spherical equivalent was significant, for both summers $(r=0.25, p=0.008)$, and winter $(r=0.243$, $p=0.010$, Figure 1 ). In summers, 85 (77.3\%) individuals reported having sunny weather most of the days, while 25 $(22.7 \%)$ individuals reported having some cloudy days. In winters, only 56 (50.9\%) people described having a sunny day usually, while 41 (37.3\%) and 13 (11.8\%) recounted having some and mostly cloudy days, respectively. Activity time was not associated with myopia, neither were reading, writing, using computers, and watching TV, even though some studies report conflicting results with near work. A negative association between time outdoors and time spent reading and writing, was found for winter weekdays, (Spearman's $r=-0.214, p=0.025)$. This association may be due to more people remaining indoors due to the weather in winters.

Both Education and Time outdoors for summers and winters were significant in the multivariate logistic analysis (Tables IA $\& B$ ), with those spending $\leq 2$ hours being more myopic in both summers (OR:3.244, SD: 1.370-7.682) and winters (OR: 3.404, SD: $1.392-8.324)$ than those spending more than two hours. The higher protective effect of time outdoors in winters may be due to the higher time interval set for the analysis, which might mitigate the effects of weather patterns noted in winters. Therefore, it is conceivable that significant sunlight exposure occurs with less time outdoors in summers, because of the better weather conditions, as noted in this study.

\section{ETHICAL APPROVAL:}

This study was approved by the Ethical Review Committee of Fauji Foundation Hospital, Rawalpindi, Pakistan.

\section{PATIENTS' CONSENT:}

Informed consents were obtained from all participants or their guardians.

\section{CONFLICT OF INTEREST:}

The authors declared no conflict of interest.

\section{AUTHORS' CONTRIBUTION:}

SAHN: Conceived and planned study design.

ZUR: Organised data acquisition and analysis.

TN: Supervised intellectual contents.

AR: Content writing and editing.

HR: Contributed in data collection.

NO: Data entry and analysis.

\section{REFERENCES}

1. Holden BA, Fricke TR, Wilson DA, Jong M, Naidoo KS, Sankaridurg $P$, et al. Global prevalence of myopia and high myopia and temporal trends from 2000 through 2050. Ophthalmology 2016; 123(5):1036-42. doi: 10.1016/j. ophtha.2016.01.006.

2. Haarman AE, Enthoven CA, Tideman JW, Tedja MS, Verhoeven VJ, Klaver CC. The complications of myopia: A review and meta-analysis. Investigative Ophthalmol Visual Sci 2020; 61(4):49. doi: 10.1167/iovs.61.4.49.

3. Williams KM, Bentham GC, Young IS, McGinty A, McKay GJ, Hogg $R$, et al. Association between myopia, ultraviolet $B$ radiation exposure, serum vitamin $D$ concentrations, and genetic polymorphisms in vitamin $D$ metabolic pathways in a multicountry European study. JAMA Ophthalmol 2017; 135(1):pp.47-53. doi: 10.1001/jamaophthalmol. 2016.4752.

4. Lin Z, Gao TY, Vasudevan B, Ciuffreda KJ, Liang YB, Jhanji V, et al. Near work, outdoor activity, and myopia in children in rural China: The Handan offspring myopia study. BMC Ophthalmol 2017; 17(1):203. doi: 10.1186/s12886017-0598-9.

5. Humayun Q, Iqbal R, Azam I, Khan AH, Siddiqui AR, Baig-Ansari N. Development and validation of sunlight exposure measurement questionnaire (SEM-Q) for use in adult population residing in Pakistan. BMC Public Health 2012; 12(1):421. doi: 10.1186/1471- 2458-12-421.

6. Jin JX, Hua WJ, Jiang $X, W u X Y$, Yang JW, Gao GP, et al. Effect of outdoor activity on myopia onset and progression in school-aged children in northeast China: The sujiatun eye care study. BMC Ophthalmol 2015; 15(1):73. doi: 10.1186/s12886-015-0052-9. 